\title{
The Information Literacy Education and the Cultivation of College and University Students' Innovative Ability
}

\author{
Wei DU*, Shi-hui WANG and Hua-ling WU \\ Library, University of Jinan, Jinan, Shandong, China \\ ${ }^{*}$ Corresponding author
}

\begin{abstract}
Keywords: Information Literacy Education; College and Uiversity Students; Innovative Ability; High Education.
\end{abstract}

\begin{abstract}
Cultivating innovative talents is the goal of Chinese current reform and transformation of university and college education. Innovative talents' information literacy education and cultivation of innovation ability promote each other and develop together. The current situation of the innovative ability of Chinese college and university students also shows that their information awareness, information ability and information ethics and so on must be strengthened in order to create qualified talents with innovative ability.
\end{abstract}

\section{Introduction}

In the Report of the 16th National Party Congress, it is pointed out that the innovation is the soul of the nation and an inexhaustible motive force for the prosperity of the country. In the Report of the 19th National Party Congress, it was also pointed out that innovation is the primary driving force for development and the strategic support for the construction of a modern economic system. This shows that innovation has become the most significant feature of this era, and innovation essentially relies on the talents with innovative abilities. College and university play an important role in cultivating and practicing innovative abilities. The Outline of the National MediumLong-Term Education Reform and Development Plan (2010-2020) states, "we must give full play to the important role of colleges and universities in the national innovation system and encourage them to contribute to knowledge innovation, technological innovation, national defense science and technology innovation, and regional innovation, and promote the interaction between scientific research and teaching, and combine the cultivation of innovative talents [1], which puts forward higher requirements for the mission of cultivating talents in colleges and universities, that is, training top-notch innovative talents. In the information society, we must have information thinking and have a strong information awareness to innovate. In the context of big data, we must fully understand the existing research results and relevant information in order to innovate. We must have very skilled and professional abilities of information retrieval, information screening, and information analysis and processing, information management, information exchange and expression, and information integration that can achieve innovation. In the internet era, integrity is the lifeline of innovation. Only through the constraints of information ethics can we ensure true innovation. Undoubtedly, from the perspective of information literacy education, it is of great significance to explore ways to improve college university students' innovative ability.

\section{Status Quo of Chinese University Students' Innovation Ability}

At first, the enrollment of college students in our country lacks the assessment of students' innovative ability, and only relies on their results of the written college entrance examinations, and rarely pays attention to their ability to innovate at the senior high school level. When entering a university, in the specific innovation and practice activities, many students lack patience and are anxious to achieve success. When they encounter failures in their studies, they lose interest and cannot persist for a long time. This is the main reason that causes the lack of innovative ability of today's college and university students. Secondly, the enrollment of college and university causes the school's various resources to be relatively tight, which is unable to provide students with a good 
environment for innovation, and many students lack of information literacy, let alone create conditions to improve their ability to innovate, which seriously limits the students' ability to innovate. Moreover, for a long time, college and university has paid too much attention to the teachers' scientific research achievements in the appointment of teachers' professional title, the construction of teams, and the distribution of treatment, which led teachers to neglect the cultivation of students' information literacy and to be unwilling to participate in the cultivation of students' innovative abilities. The weak sense of innovation makes it difficult to guide students with more innovative abilities.

In our country, the higher education develops rapidly, and the scale of enrollment in college and university is constantly expanding, but at the same time there are also difficulties in employment, which results in a relative surplus of talents. The root cause of this phenomenon is that the talents cannot adapt well to the society development. Diversification of the economic development of modern society has occurred, the mode of economic growth has also changed, and knowledge has been updated rapidly. The knowledge that students learn in school often lags behind, and students have already been eliminated before they graduate. The employer not only requires that college and university students have solid professional knowledge, but also requires that they have diversified literacy that suits the requirements of different positions. Therefore, we must cultivate university and college students who adapt to the characteristics of modern society, improve their information literacy in order to prepare for lifelong learning. The higher education in China has always been following expert education, which is too weak for students' culture nurture, and too narrow for professional education, and has a certain utilitarian orientation and commonality constraints. As a result, the students lack the innovation sense and innovation ability, and it is difficult for them to adapt to society, and serve the society. On the one hand, this has caused the waste of talents, and on the other hand, the society's demand for talent has not been met, which leads to the urgent need of the talents in the society.

Chinese colleges and universities are more accustomed to passing on existing knowledge and adopting habitual education methods. Examinations are also standardized test questions and routine answers, and students are rarely encouraged to explore questions. This kind of education model is a "known-seeking-solution" model, which greatly restricts the cultivation of students' intelligence and the creation of originality. Innovation consciousness and creative ability not only fail to train, but gradually shrink. The true creative process is that no one provides "known", and no one provides "seeking", and relies solely on their own sense of creative consciousness, to discover "known" and "seek" keenly, and looking for answers, all require college students must have the information literacy.

\section{The College and University Students' Innovative Ability and Information Literacy Education}

\subsection{Information literacy education promotes the cultivation of innovation ability}

The essence of information literacy education is an innovative education and an integral part of higher education [2], whose aims are to cultivate students' innovation sense and innovation ability and which provides a fundamental guarantee for the cultivation of innovative talents. While cultivating student's literature information retrieval skills and computer application techniques, it has a significant impact on the cultivation of the university students' comprehension ability and adaptability to the modern information environment, and the self-consciousness, initiative, predictability and independence of the use of information. Information literacy education plays a positive role in cultivating college students' innovative thinking, self-learning ability, innovative ideas, and innovative practice [3]. Only when the college and university students have the information literacy can they acquire, process, and utilize the knowledge information resources in the information society environment, thus forming the independent innovation consciousness and comprehensive innovation ability. Information literacy education in colleges and universities is mainly reflected in two aspects: (1) the good information literacy can support the creative learning. 
(2) The information literacy education can further strengthen and improve the quality characteristics of innovative talents [4].

\subsection{To improve the innovation ability can improve the information literacy level}

To have the innovation ability, the college and university students must have the innovation awareness. Innovation awareness is the source of information awareness, the driving force of information ability mining, and information awareness is the accelerator of innovation awareness. Information ability is an important part of innovation ability, and information literacy is reflected in the process of innovation [5]. Information literacy education is an important link in cultivating innovative talents, which must take the concept innovation as the starting point, the theoretical innovation as the guidance, the institutional innovation as the basis, the technological innovation as the means, and the teaching innovation as the goal. We should fully carry out the information literacy education to promote the cultivation of innovative talents [6].

\subsection{Information literacy education and innovation ability cultivation promote each other and develop together}

The relationship between the cultivation of innovative talents and information literacy education is mainly reflected in four aspects. (1) The process of cultivating innovative talents is to perfect the process of innovative talents' information literacy. (2) The ultimate goal of information literacy education is to cultivate innovative talents in 21 st century. (3) The information literacy education plays an important role in promoting the innovative talents. (4) Paying attention to the cultivation of innovative talents can make the information literacy education make greater progress [7]. There are many commonalities between the information literacy education and the innovative talents cultivation, and also there are many abilities in both of them, which emphasize non-static properties. In the process of cultivating students' information literacy and innovation abilities, not only compliance with social soft environments such as culture, morality, and law is emphasized, but also the critical thinking is emphasized. Both of them are committed to lifelong learning [8]. In short, strengthening information literacy education is a catalyst for accelerating the cultivation of innovative talents, and innovation consciousness is a booster for strengthening information literacy education. The two complement each other [9].

\section{Information Literacy Education Measures Based on the Cultivation of Students' Innovative Ability}

The ultimate goal of information literacy education is to cultivate qualified students with innovative abilities by cultivating students' information awareness, information abilities, and information ethics.

\subsection{Information awareness training}

Information awareness is the degree of people's sensitivity, insight to information, and the level of awareness, feedback, analysis, judgment, and absorption of information. Only with keen sensibility to information can there be timely prompt the information behavior. Information awareness is one of the main components of information literacy and it is the basic source and prerequisite for creative thinking of university and college students. In the era of rapid economic development, there are many kinds of information resources, which contain numerous factual data, methods, theories, inventions, and scientific achievements, which have the value of satisfying people's information needs, but this satisfaction implementation depends on people's level of information awareness. In general, the same kind of information, if used by those with a stronger level of information awareness, may exert a higher value of use. If it is used by those with a general sense of information, its value can only play a part or even be completely submerged. If a person's information awareness has not yet reached the point where he or she has discovered the value of certain information, or has not actually grasped the use methods or is not good at using modern technologies, he or she is unable to incorporate this information into his or her own use, let alone 
innovation. Therefore, we must strengthen the cultivation of university and college students' information awareness.

\subsection{Information abilities training}

Information abilities mainly include the ability to recognize, acquire, identify, retrieve, process, use, analyze, synthesize, communicate with information, and master the modern information technologies [10]. Not only should we train the university and college students to use the Internet, such as databases and professional academic websites to obtain information, but also should we train them to use QQ, e-mail to upload and download various media information, and so on. The university and college should take the information ability cultivation as the core, drive the information literacy education to spread out in a comprehensive way, and improve the students' innovative ability by reforming teaching plans, teaching methods, and teacher evaluation systems. The university and college should not only actively encourage students to participate in scientific research activities, pay attention to the cultivation of students' information ability, strengthen students' sensibility and insight, but also pay attention to cultivating students' creative thinking, improve the efficiency of students' information acceptance and information feedback, and enable students to combine their studies with majors, access to information, and analyze and evaluate information. At last, the university and college should focus on the improvement of the students' information capabilities, and ultimately achieve the purpose of training and improving the students' innovative ability.

\subsection{Information ethics training}

Information ethics refers to the sum of moral awareness, moral norms, and moral behaviors that are used to regulate the various social relationships that arise during the information activities such as the collection, processing, storage, dissemination, and utilization of information. Information ethics is formed on the premise of information technology development. In daily life, it is not difficult to find that some university and college students are not very familiar with the ethics, laws, and other issues involved in the use of computer networks, and hold indifferent attitudes to the infringement of intellectual property rights and the violation of personal privacy. Therefore, the college and university and other related departments should take responsibility for cultivating the students' information ethics, and make full use of their educational advantages to promote information ethics and information regulation vigorously. They can also carry out the special education and discussion on various ethical issues raised on the Internet, so that the students consciously abide by the code of ethics without bad behaviors, conscientiously shape the healthy personality to access networks, and develop good information ethics and behavioral habits, distinguish the relationship between citation and infringement in the process of innovation and develop a correct view of information ethics.

\section{Conclusion}

Based on the current theory and practice of cultivating students' innovative spirit and innovative ability, the college and university should pay special attention to the key role of the teachers in the process of cultivating students' innovative ability. In the process of information literacy education, the teachers should make the students be able to fully express themselves and cultivate students' multi-directional and critical thinking. In today's world, knowledge economy and knowledge innovation have become the mainstream that leads the development of the world. The competition among nations is the competition for talents in the final analysis. Colleges and universities as the advanced institutions for cultivating talents can cultivate high-quality talents only by strengthening the cultivation of students' innovative ability. Improving students' innovative ability has become an urgent task for the reform and development of higher education. Information literacy is an indispensable basic condition for cultivating students' innovative ability. Strengthening students' information literacy education plays an important role in cultivating students' innovative ability. 


\section{References}

[1] Working Group Office of the Outline of the National Medium and Long Term Education Reform and Development Plan. Outline of the National Medium and Long Term Education Reform and Development Plan (2010-2020) [EB/OL]. [2010-7-29] [2018-5-22] http://old.moe.gov.cn/ publicfiles/business/htmlfiles/moe/info_list/201407/xxgk_171904.html

[2] Wang Junlan, Zhang Yanli. Information Literacy Education and Cultivation of College Students' Creative Ability in 21st Century [J]. Journal of Medical Informatics, 2008 (5): 84.

[3] Wong Meichun. The Role of Information Literacy Education in Cultivating Innovative Talents [J]. Legal System and Society, 2006 (12): 189.

[4] Li Xiaoxin. Information Literacy Education and Cultivation of Innovative Talents. Improving the Scientific Literacy of All People and Building an Innovative Country - 2006 Proceedings of the China Association for Science and Technology Annual Conference [C]. Beijing: China Association for Science and Technology, 2006: 219.

[5] Xing Yanli. The Reform of Information Literacy Education and Cultivation of College and University Students' Innovative Ability [J]. Library Work and Study, 2009 (3): 93.

[6] Zhuang Qing. The Information Literacy Education and the Cultivation of Innovative Talents [J]. 2006 (5): 159-160.

[7] Deng Yawen. On Relationship Between Information Literacy Education and Innovation Talent Education [J]. The Library Journal of Henan, 2007 (3): 20-22.

[8] Zhao Naixuan, Zhou Jingzhen, Huang Chunjuan. The Information Literacy Education and the Cultivation Innovative Talent in Library [J]. Library Theory and Practice, 2007 (6): 24.

[9] Cheng Yang. The Information Literacy Education and the Cultivation Innovative Talent [J]. Study Monthly, 2013 (2): 69-71.

[10] Fan Xingrong. The Reflection on and Exploration about the Improvement of Students' Information Literacy by University Library under the Environment of Big Data [J]. Journal of Academic Library and Information Science, 2014 (6): 89-93. 